\title{
Licenciatura em Educação do Campo: espaço de garantir direito humano e social
}

\author{
Degree in Rural Education: space to guarantee humanand social rights
}

\author{
Célia Beatriz Piatti \\ Universidade Federal de Mato Grosso do Sul \\ celiabpiatti@gmail.com
}

\begin{abstract}
Resumo: As políticas educacionais são formuladas pelo Ministério de Educação e, uma vez criadas, tornam-se um compromisso social para as instâncias responsáveis. Nosso estudo aponta o papel da universidade ao implantar um curso de licenciatura em Educação do Campo, cuja responsabilidade é incluir os sujeitos do campo e garantir a sua permanência nesse espaço. Para tanto, indaga-se: Ao garantir o ingresso dos acadêmicos na universidade, há a garantia de permanência? O discurso da inclusão é questionado no seio da universidade? Como a universidade tem garantido essas políticas de inclusão? Nesse sentido, nosso estudo tem base na defesa da Educação do Campo como direito humano e social. Considera-se que a universidade cumpre o seu papel na inclusão desses sujeitos, mas não garante a sua permanência nesse espaço, portanto assegura-se o direito, com o discurso da inclusão, mas a ação é segregadora e excludente.
\end{abstract}

Palavras-chave: Inclusão. Exclusão. Direito.

Abstract: Educational policies are formulated by the Ministry of Education and, once created, they become a social commitment for the responsible bodies. Our study points out the role of the university when implementing a degree course in Education in the Field, whose responsibility is to include the subjects of the field and ensure their permanence in that space. Therefore, it is asked: When guaranteeing the entrance of academics to the university, is there a guarantee of permanence? Is the inclusion discourse questioned within the university? How has the university ensured these inclusion policies? In this sense, our study is based on the defense of Rural Education as a human and social right. It is considered that the university fulfills its role in the inclusion of these subjects, but does not guarantee their permanence in this space, therefore the right is guaranteed, with the inclusion discourse, but the action is segregating and excluding.

Keywords: Inclusion. Exclusion. Right. 


\section{Dialogia}

PIATTI, Célia Beatriz. Licenciatura em Educação do Campo: espaço de garantir direito humano

\section{Introdução}

Iniciamos esse texto com uma indagação: $O$ que é inclusão?Pode-se dizer que significa incluir, congregar, agrupar e tantas outras acepções que direcionam para o sentido de inserir algo ou alguém em determinada situação ou lugar.

Em se tratando de educação, há diversas discussões que difundem a necessidade de inclusão de forma geral, principalmente no ensino público. Em todas as instâncias educacionais e também nas universidades, pauta-se constantemente essa questão com as possibilidades de garantir a entrada de sujeitos que, por algum motivo, têm dificuldades ao acesso à universidade.

Nesse sentido, considera-se que as ações afirmativas para ingresso de negros, indígenas e pessoas com deficiências têm sido a possibilidade de garantir na universidade a diversidade, a garantia de direitos e a maior equidade nos espaços universitários. Nessas ações, podemos apontar a inclusão das populações do campo, segregadas e silenciadas por décadas frente às políticas públicas.

Posto isso, este estudo tem a intenção de trazer para a discussão uma experiência com a implantação da licenciatura em Educação do Campo da Universidade Federal de Mato Grosso do Sul, iniciada no ano de 2013, a qual apresenta uma experiência de inclusão frente à oferta do Ministério de Educação (MEC), via edital de oferecimento de vagas específicas para quem vive e/ou trabalha no campo, na perspectiva de garantir um direito constitucional. Nesse sentido, "[...] a Educação do Campo como direito para a diversidade dos povos do campo é uma questão que se insere na luta pelos direitos humanos." (PIRES, 2012, p.13).

Frente a essa luta, indaga-se: Ao garantir o ingresso dos acadêmicos na universidade, há a garantia de permanência? O discurso da inclusão é questionado no seio da universidade? Como a universidade tem garantido essas políticas de inclusão?

\section{A licenciatura em Educação do Campo em contexto}

A Universidade Federal de Mato Grosso do Sul (UFMS), no ano de 2013, em acordo ao edital no 2 SESU/SETEC/SECADI/MEC, de 31 de agosto de 2012, que visava a criação de licenciaturas em Educação do Campo com objetivos previstos no Programa de Apoio à formação Superior em Licenciatura em Educação do Campo (PROCAMPO), tendo como aporte a resolução CNE/CEB n ${ }^{\circ} 1$, de 3/4/2002, ao Decreto $n^{\circ} 7.352$, de 04/11/2010 em acordo com o Programa 
PIATTI, Célia Beatriz. Licenciatura em Educação do Campo: espaço de garantir direito humano e social

Nacional de Educação do Campo (PRONACAMPO), criou a Licenciatura em Educação do Campo (LeduCampo). (PROJETO DE CURSO, 2014).

Cabe ressaltar que o PROCAMPO foi criado com o objetivo de implantar cursos de licenciatura em Educação do Campo, na modalidade presencial, em regime de alternância e o PRONACAMPO tem como objetivo um conjunto de ações integradas que visam a qualidade da Educação do Campo, no que tange à formulação do material didático específico e à formação de professores, abrangendo todas as etapas de ensino e modalidades.

Em 2013, iniciou- se a organização do curso, que foi efetivado no ano de 2014, para o qual foram selecionados em concurso específico, de acordo com o edital PROGEP no 63, de 18 de Dezembro de 2013, sete docentes: quatro da área de ciências humanas e sociais, um da área de linguagem e dois da área de matemática.Posteriormente, no ano de 2015, sob o edital PROGEP, $n^{\circ} 85$, de 02 de outubro de 2014,mais oito docentes foram selecionados, sendo, dois da área de educação, dois da área de agrárias, um da área de música e um da área de matemática.Em conformidade com o edital PROGEP, n²4, de 12 de junho de 2013, foram selecionados, também via concurso,três técnicos assistentes.

De acordo com os critérios estabelecidos, o curso contou com edital próprio de vestibular, que objetivou privilegiar quem vive, trabalha ou tem vínculo com o campo. Foi organizado em regime presencial, na modalidade de alternância, cuja proposta está ancorada em tempos alternados, pois a alternância é "[...] uma pedagogia que tem a sua gênese nas necessidades das populações camponesas, por isso é organicamente vinculada ao campo.” (CORREIA; BATISTA, 2012, p. 173). Para responder as suas especificidades, foi estruturado em dois momentos: tempouniversidade (momento em que os alunos permanecem na universidade com aulas teóricas) e tempo-comunidade (momento em que os alunos, em suas comunidades, articulam os conteúdos aos saberes do campo). Considera-se que a alternância tem sido a possibilidade de contribuir, além da sua especificidade teórico-metodológica, com o ingresso desses estudantes, que podem continuar trabalhando em suas comunidades, articulando esse trabalho com os saberes adquiridos na universidade, uma vez que a alternância supõe vincular o tripé escola, família e trabalho.

O curso foi criado com ênfase em três áreas de conhecimento: Linguagem e Códigos, Matemática e Ciências Humanas e Sociais. Os acadêmicos matriculados pertencem a várias localidades do estado de Mato Grosso do Sul: jovens que finalizaram o Ensino Médio, adultos que cursaram a Educação de Jovens e Adultos (EJA), portanto em formação inicial e, em sua grande maioria, professores com formação em diferentes áreas do conhecimento e que buscam na licenciatura em Educação do Campo uma formação mais específica sobre a escola do campo. 
PIATTI, Célia Beatriz. Licenciatura em Educação do Campo: espaço de garantir direito humano

Em seu Projeto de Curso, a proposta apresenta uma base que

É pedagógica, mas também filosófica, política, ideológica, engajada. O Marco Referencial contextualiza e problematiza a educação escolar rural, concebida política e historicamente pelos fazendeiros, como processo educativo limitador. Em contraponto, a práxis da Educação do Campo que é evidenciada como potencialização de ações afirmativas e dialógicas. (PROJETO DE CURSO, 2014, p. 7).

Nessa perspectiva e concepção,

O curso pretende provocar os alunos a repensarem, filosoficamente, o ser humano e a vida no campo como espaços e tempos de ser, de estar, de conviver, de produzir bens materiais e imateriais, na possibilidade de que os alunos compreendam as ligações das partes com o todo e do todo com as partes, na busca da sustentabilidade local mediada pela organização comunitária, o coletivo, a mística, a agricultura familiar (PROJETO DE CURSO, 2014, p. 7).

Também encontra- se no Projeto de Curso (2014) a perspectiva que aponta a alternância com a finalidade de promover o encontro entre os alunos que residem em diferentes locais e que estão no curso em diferentes áreas, oportunizando que conheçam e reconheçam as diversas experiências desenvolvidas no Estado, por meio de visitas conduzidas pelos docentes às escolas do campo, às comunidades, às associações e aos assentamentos, com o objetivo de construir uma visão concreta dos diferentes contextos da Educação do Campo em Mato Grosso do Sul.

Todas as atividades realizadas são acompanhadas por docentes do curso com orientações, consolidando e contribuindo para a estruturação do currículo e da proposta metodológica para que estejam em constante construção, com vistas à efetiva participação dos alunos. Nesse sentido, “[...] a matriz curricular do curso tem sua base na concepção de que apenas inserir-se na universidade não é suficiente para alterar as estruturas já consolidadas nesse processo de formação, mas pode, com o trabalho efetivado, contribuir para a transformação" (PROJETO DE CURSO, 2014, p.7).

A partir dessa organização, pretendeu-se nesse curso uma formação agregada ao contexto em que se insere, ou seja, uma formação em processo contínuo, aliada ao contexto e às necessidades locais, no entanto não ignorando os debates gerais da sociedade, integrando assim, questões singulares sem perder de vista as questões universais, necessárias ao debate sobre a Educação do Campo.

\section{A educação do e no campo}

Para iniciar nossa discussão faz-se necessário compreender a concepção de Educação do Campo e, nesse sentido, Caldart (2002) aponta a diferença entre educação do e no campo: "No: o 
povo tem direito de ser educado no lugar onde vive. Do: o povo tem direito a uma educação pensada desde o seu lugar e com a sua participação, vinculadas a sua cultura e às suas necessidades humanas e sociais". (CALDART, 2002, p.26).

Para Fernandes (2009):

A Educação do Campo "é um conceito cunhado com a preocupação de se delimitar um território teórico. Nosso pensamento é defender o direito que uma população tem de pensar o mundo a partir do lugar onde vive, ou seja, da terra onde pisa, melhor ainda a partir de sua realidade". (FERNANDES, 2009, p. 141).

Nesse mesmo sentido, Molina (2009) assevera que “[...] para o funcionamento de uma escola que possa ser considerada "do campo" é necessário o reconhecimento e a valorização da identidade de seus sujeitos" (MOLINA, 2009, p,32). Tendo em vista tais questões, é importante compreender que as populações do campo buscam seus direitos e, um deles, é a educação. Logo, considera-se que é necessário conhecer e reconhecer a cultura do campo, a luta e a resistência para viver no campo e do campo, com perspectivas de consolidar a identidade desse espaço.

Em Pires (2012), encontramos que:

É fundamental reconhecer e conhecer, respeitar e resgatar a afirmação da diversidade sociocultural dos povos do campo. O campo precisa ser compreendido como modo de vida sociocultural no sentido que sejam afirmadas as suas identidades, bem como as suas lutas e organizações. (PIRES, 2012, p. 43).

Frente a essas questões, é possível conceber a inclusão necessária para essa população no seio da universidade, portanto, surge um questionamento: Como se inscrevem esses cursos na universidade?

De acordo com Neto (2011),

Os cursos de licenciatura do campo inscrevem-se dentro de propostas políticas que podem ser inovadoras para a escola e para as relações sociais, pois numa sociedade de classes, com interesses diferenciados, o compromisso com o trabalhador do campo e com a escola que interessa aos setores populares é parte da disputa hegemônica para a conquista de uma sociedade mais justa. (NETO, 2011, p. 25).

Logo, cabe ressaltar a importância de compreender o espaço que esse curso ocupa na universidade, pois depreende -se que, conforme Antunes-Rocha e Martins (2012), há três questões a serem alvo de reflexão em relação à universidade a fim de cumprir a sua função.Em primeiro lugar, 
Pode significar o cumprimento de sua função educativa do ponto de vista inclusivo e democrático, ao acolher em seu seio grupos sociais que instauram novas formas de pensar e fazer o mundo, isto é, produzem novos conhecimentos e desejam partilhá-los e legitimá-los em um ambiente historicamente comprometido com a produção e socialização dos saberes. (ANTUNESROCHA; MARTINS, 2012, p. 17).

Para as autoras, em segundo lugar, considerando o uso da preposição "de” nas expressões - "da terra", "do campo",

Pode significar um pertencimento - à terra, ao Campo, de determinados conhecimentos que, em via de mão dupla, serão partilhados com a academia. Culturalmente, significa aprender com a Terra, aprender com o Campo os modos genuínos de olhar para a vida do homem, em sintonia com a vida na natureza. (ANTUNES-ROCHA, MARTINS, 2012, p. 17).

Em terceiro lugar, é função da universidade "O compromisso acadêmico e político com o processo de construção de uma sociedade justa, fraterna e sustentável” (ANTUNES-ROCHA; MARTINS, 2012, p.17). As autoras seguem afirmando que são muitos os motivos que envolvem a universidade em um projeto de formação de professores para atuação nas escolas do campo, principalmente a parceria com os movimentos sociais para juntos assumirem o compromisso de dar ao sujeito do campo o direito de "ocupar o seu papel como sujeito nessa construção".

Ocupar esse espaço é um direito, é a possibilidade de produzir vida, em todos os aspectos e sentidos de educação, de trabalho e de convivência, que partem da luta e da conquista de trabalhadores do campo.

A escola do campo pode ser considerada como resultado da luta dos trabalhadores do campo em conjunto com os movimentos sociais,pois há desafios a suplantar que levam em conta, conforme assevera Fernandes, Cerioli e Caldart (2009), superar a dicotomia urbano-rural, já que há uma ideia geral de que a escola urbana é melhor que a escola do campo, que o espaço urbano é moderno e o do campo é atrasado. Uma vez que há uma visão da sociedade de que o campo é um espaço atrasado, portanto seus sujeitos também são vistos como estando em atraso.

Para Arroyo (2006), é preciso indagar: Que imagem do campo afirmam? O autor afirma que "[...] os movimentos sociais revertem essas imagens e nos obrigam a enxergá-los como sujeitos dinâmicos, tensos, politizados, organizados.” (ARROYO, 2006, p. 10)

Arroyo reitera:

O campo precisa ser visto não mais como lugar de atraso, de tradicionalismo, de inércia, mas território social e cultural dinâmico, como lugar de produção de vida, trabalho, cultura, saberes e valores. Como terra que educa, lugar de educar e não educar. De produção de solidariedades e identidades culturais. De formação de sujeitos humanos. (ARROYO, 2006, p. 10). 
De forma complementar, ressalta-se a tímida iniciação da reforma agrária, pois os agricultores lutam por política agrícola diferenciada para a agricultura familiar e, desse modo, o autor defende que a agricultura familiar é muitas vezes ameaçada pelo agronegócio, por isso é importante compreender que "A produção e o trabalho são princípios educativos [...] é um movimento pedagógico, a defesa da terra e do trabalho, as formas de produção agrícola são vistas também pelo movimento do campo como educativas, formadoras”. (ARROYO, 2006, p. 11).

Reconhecer esse espaço nos permite avançar na ideia de que a inclusão dos povos do campo na universidade é a garantia de um direito, mas há também o grande desafio: a permanência desses estudantes no contexto universitário. Em relação à questão cabe saber que há muitas concepções sobre o conceito de Educação do Campo, bem como de sua interpretação da realidade, mas segundo Molina (2011,p.185) um consenso se faz presente: “[...] a inadiável necessidade de formação de educadores capazes de compreender e trabalhar processos educativos a partir das especificidades dos modos de produção e reprodução da vida no campo”.

Diante dessa constatação de que o direito de adentrar a universidade para essa população é garantia constitucional, amparamos no questionamento de Molina (2011, p.196) ao indagar: “A construção dessas licenciaturas, a presença de diferentes movimentos sociais do campo dentro das universidades poderão ajudar-nos na tarefa de reconquistarmos esses territórios para dentro das universidades?”

De acordo com Caldart (2002),

Somos herdeiros e continuadores da luta histórica pela constituição da educação como direito universal, de todos:um direito humano, de cada pessoa em vista de seu desenvolvimento pleno, e um direito social, de cidadania ou de participação mais crítica e ativa na dinâmica da sociedade. Como direito não pode ser tratada como serviço nem como política compensatória; muito menos como mercadoria. (CALDART, 2002, p. 26).

Ao considerarmos essa ideia de "herdeiros e continuadores da luta pela educação como direito", a inclusão dessa população na universidade é a garantia desse direito a uma educação pública de qualidade, que acrescente a esses sujeitos não somente os conhecimentos científicos, mas também os saberes que surgem da vida no campo.

Saberes que, de acordo com Arroyo (2009, p.81), é um direito. Indaga o autor: "Como a escola vai trabalhar a memória, explorar a memória coletiva, recuperar o que há de mais identitário na memória coletiva? Como a escola vai trabalhar a identidade do homem e da mulher do campo"?

O autor alerta que a escola deve se preocupar com o direito ao saber e ao conhecimento, já que ela deve “[...] incorporar o saber, a cultura, o conhecimento socialmente construído". (ARROYO, 2009, p.81) e que é preciso certo cuidado, uma vez que os [...] "saberes construídos 
PIATTI, Célia Beatriz. Licenciatura em Educação do Campo: espaço de garantir direito humano

historicamente nem sempre estão no saber escolar, nem tudo que está no currículo urbano é social, logo não tem que chegar à escola do campo". (ARROYO, 2009, p. 81).

Frente a tais questionamentos, Arroyo (2009) afirma que, para o projeto de Educação Básica, é preciso que a estrutura tenha a mesma lógica dos movimentos sociais, ou seja,

Que seja inclusiva, democrática e igualitária, que trate com respeito e dignidade as crianças, jovens e adultos do campo, que não aumente a exclusão dos que já são excluídos, tarefa urgentíssima para a construção da educação básica do campo: criar estruturas escolares inclusivas. (ARROYO, 2009, p. 86).

Essa condição nos aponta o papel da universidade ao criar um curso de licenciatura em Educação do Campo, um curso que tem a responsabilidade de incluir esses sujeitos e garantir a sua permanência nesse espaço, que os inclua como sujeitos de direitos e que tenha um projeto de curso com perspectivas de apontar uma proposta de formação específica, a qual articule os conhecimentos científicos com possibilidades de ampliação dos debates referentes à Educação Básica, levando em conta a história dessa população, marcada por exclusão constante.

Cabe então, para a universidade, promover nesse curso o debate que leve os acadêmicos em formação a compreender esse contexto ávido de transformação, o que resulta em uma responsabilidade política e social da universidade.

É um avanço compreender a concepção real de Educação do Campo para contribuir com uma visão mais abrangente e crítica sobre o que é a Educação do Campo e suas finalidades. Para Leontiev (2004, p. 293), numa sociedade dividida em classes há “[...] enormes diferenças e condições do modo de vida, da riqueza, da atividade material e mental, do nível de desenvolvimento das formas e aptidões intelectuais." Afirma o autor que essa desigualdade não se refere às diferenças biológicas, mas é “[...] produto da desigualdade econômica, da desigualdade de classes e da diversidade consecutiva das suas relações com as aquisições que encarnam todas as aptidões e faculdades da natureza humana, formadas no decurso de um processo sócio-histórico." (LEONTIEV, 2004, p. 293).

Tomando essa ideia como base, podemos entender que "[...] a concentração de riquezas materiais na mão de uma classe dominante é acompanhada de uma concentração da cultura intelectual nas mesmas mãos" (LEONTIEV, 2004, p. 294). O autor segue afirmando que, embora as criações pareçam existir para todos,

[...] só uma ínfima minoria tem o vagar e as possibilidades materiais de receber a formação requerida, de enriquecer sistematicamente os seus conhecimentos[...] homens que constituem a massa da população, em particular da população rural, têm de contentar-se com o mínimo de desenvolvimento cultural necessário à produção de riquezas materiais no limite das funções que lhes são destinadas. (LEONTIEV,2004, p. 294). 
Nesse sentido, nesse formato de sociedade, apesar de toda a exclusão existente, consideramos a escola como um espaço em condições de acolher a maioria, mas é preciso pensar o desafio de concretizar a sua permanência frente a um ensino de qualidade e ações inclusivas que garantam essa permanência.

Sabemos que apenas a educação formal não é capaz de transformar a sociedade, mas é um caminho que, se bem planejado - com intencionalidades voltadas à possibilidade de transformação, ancoradas no ato político-pedagógico que se pretende para essa ação -aponta para o fato de que a formação de professores exige conhecimentos gerais e específicos, mas, sobretudo, exige conhecer os princípios da Educação do Campo para que a ação seja efetiva na futura prática docente.

Depreende-se que a formação proposta na licenciatura em questão, como nas demais espalhadas pelas universidades do país, assume, antes de tudo, o compromisso de fortalecer elos entre as escolas e as comunidades, para que haja diálogo nos saberes que são produzidos: no trabalho do camponês, nas escolas do campo, na universidade, nos movimentos sociais, nas lutas e em tudo que é produzido nas comunidades campesinas.

\section{A inclusão: um direito de todos?}

Tomando como base o texto das Diretrizes Operacionais para a Educação do Campo, discutir a educação como direito do povo brasileiro nos remete à história das constituições no Brasil. Segundo o referido documento, a abrangência desse tema,

[...] a partir de 1934, em que pese o Brasil ter sido considerado um país eminentemente de origem agrária, a educação rural sequer foi mencionada nos textos constitucionais de 1824 e 1891, o que nos remete o descaso com a educação do campo e os resquícios de matrizes culturais vinculadas a uma economia agrária apoiada no latifúndio e no trabalho escravo (DIRETRIZES OPERACIONAIS,2002, p. 7).

Já na Constituição de 1988, configura-se em um marco que amplia as obrigações do Estado no que se refere ao setor educacional, pois afirma a garantia de direitos importantes para a população do Campo.

Segundo Pires (2012), essa garantia de direitos fez com que a constituição se tornasse

A expressão dessas reivindicações e, consequentemente, se constituísse em um marco para a educação brasileira, ao incorporar entre os direitos sociais e políticos o acesso de todos(as) brasileiros(as) à educação escolar como uma premissa básica da democracia. (PIRES, 2012, p. 90). 
PIATTI, Célia Beatriz. Licenciatura em Educação do Campo: espaço de garantir direito humano

A autora afirma que, nesse contexto, “[...] a educação rural foi considerada como direito, mas um direito, ainda inspirado no paradigma urbano.” (PIRES, 2012, p. 90). Nesse sentido, a constituição de 1988:

Foi um instrumento balizador para que as constituições estaduais e a LDB/ 9.394/96(Lei de Diretrizes e Bases da Educação Nacional) focalizasse a educação rural no âmbito do direito à igualdade e do respeito às diferenças, possibilitando discutir como seria a oferta dessa educação para os povos do campo, buscando adequar a Educação Básica às especificidades locais. (PIRES, 2012, p. 90).

A Lei de Diretrizes e Bases da Educação Nacional (LDBN) aponta a educação rural e seu direito à igualdade e ao respeito às diferenças quando afirma a necessidade de adequar a educação básica às especificidades locais, tendo em vista a possibilidade de organizar seus períodos escolares em ciclos, como a alternância, respeitando o ciclo agrícola e as condições climáticas, bem como a necessidade de adaptar os conteúdos escolares e as metodologias apropriadas às necessidades e interesses do aluno advindo do campo.

Há também que se destacar o Programa Nacional de Reforma Agrária (Pronera), criado em 1988, em parceria com os movimentos sociais, as universidades públicas e o Instituto Nacional de Colonização e Reforma Agrária (INCRA). Segundo Pires (2012, p.97), “O Pronera possibilitou condições para a implantação de oferta de cursos em diversas modalidades de ensino nas áreas de reforma agrária".

Um movimento também importante e relevante nessa luta foi o I Encontro de educadores da reforma agrária (Enera),

[...] que contou com a coordenação do MST, em parceria com a universidade de Brasília (UnB), o Fundo das Nações Unidas para a infância (Unicef), a Organização das Nações Unidas para a Educação, Ciência e Cultura(UNESCO) e a Conferência Nacional dos Bispos do Brasil(CNBB). Foi deste encontro que surgiu a proposta da I Conferência por uma Educação básica do Campo. (PIRES, 2012, p. 93-94).

Segundo a autora, um instrumento importante foi “[...] o Fundo de Manutenção e Desenvolvimento do Ensino Fundamental e de Valorização do Magistério (FUNDEF), cujos recursos promovem a universalização do acesso, com qualidade e, portanto, constitui-se em um instrumento estratégico de apoio à educação rural.” (PIRES, 2012, p. 90).

Importante ressaltar o parecer CNE/CEB 36/2001 e a Resolução CNE/CEB1/2001, que estabelecem as Diretrizes Curriculares para a Educação Básica das escolas do campo e apresentam novas possibilidades de organização da escola. Seu objetivo é uma educação emancipatória no sentido de que a prática pedagógica esteja articulada à vida no campo, o que exige profissionais qualificados e que compreendam essa necessidade, o que impõe à universidade um compromisso 
social com essa licenciatura, que deve preservar a identidade do campo e a história de sua população.

Reitera-se a importância dos movimentos sociais nessa luta pela Educação do Campo, pois participam dessa empreita desde o seu início com a I Conferência Nacional "Por uma Educação Básica do Campo" que objetivou “[...] ajudar a recolocar o rural, e a educação que a ele se vincula, na agenda política do país.” (FERNANDES; CERIOLI; CALDART, 2009, p. 22).

$\mathrm{Na}$ discussão desencadeada nessa conferência é que se rompe com a expressão "meio rural". Esse rompimento, segundo Fernandes, Cerioli e Caldart (2009),explica-se por meio da reflexão sobre o sentido do trabalho camponês, uma vez que se trata de uma educação voltada para os trabalhadores do campo.

A II Conferência "Por uma educação do campo" ocorreu em 2004 e concretizou discussões necessárias sobre a luta dos povos do campo por políticas públicas que assegurem uma educação do e no campo, reforçando a importância da agricultura familiar e da garantia de políticas públicas, bem como visando a criação, a ampliação de escolas e a formação dos professores.

Nessa perspectiva, inclui-se como garantia de direitos a criação de licenciaturas em Educação do Campo. Com a organização de grupos de trabalho para Educação do Campo na Secretaria de Educação Continuada, Alfabetização, Diversidade e Inclusão (SECADI), em 2006 iniciou-se uma experiência inicial para formação de professores com vistas a atuarem nas escolas do campo. Essa experiência contou com o engajamento das Universidades Federal de Santa Catarina (UFSC), Federal de Sergipe (UFSE), Federal da Bahia (UFBA) e Universidade Federal de Minas Gerais(UFMG). Hoje são 44 universidades que implantaram o curso de licenciatura em Educação do Campo, o que nos permite conceber um avanço para essas populações no que tange ao direito de ingresso na universidade.

Frente a esse panorama histórico, discutir e debater a igualdade de oportunidade de acesso à universidade significa respeito à diversidade, termo que aqui se refere a reconhecer as desigualdades que tornaram a população do campo excluída e segregada historicamente pelo Estado.

De acordo com Sácristán:

Se não são dadas as condições mínimas necessárias para que as desigualdades possam começar a serem corrigidas, não só estamos diante de um problema de injustiça, mas também diante do abismo entre seres humanos que não discrimina os desfavorecidos, mas que os afasta definitivamente da sociedade. (SACRISTÁN, 2001, p. 66). 
PIATTI, Célia Beatriz. Licenciatura em Educação do Campo: espaço de garantir direito humano

Nesse sentido, a inclusão é defendida como processo social, histórico, ético e político. Respeito à diversidade é uma forma de inclusão, de conceber a educação como fator de inclusão. Segundo Sacristán (2001, p.66), podemos considerar que “[...] o potencial que a educação desempenha para todos é da inclusão."

Depreende-se que nem sempre essa inclusão revela a garantia de permanência desses sujeitos na universidade, já que isso depende de como a ação tem resguardado essa diversidade, tanto nas relações pessoais, políticas e institucionais, por isso cabe indagar: Que diversidade é essa que estamos discutindo?

Entende-se que a diversidade nessa discussão pressupõe garantir que os cursos de licenciatura compreendam a Educação do Campo como uma luta que, arraigada à história brasileira, teve, desde os primórdios, seus direitos negados, silenciados e corrompidos. Cabe nessa organização institucional de construir as licenciaturas, romper o silêncio, dar vOz a esses sujeitos, compreender que, acima da inserção deles no interior da universidade, é necessário promover a sua integração, com o reconhecimento da sua história, pois, sem reconhecê-la, será impossível a sua inclusão.

Afirma-se que:

As experiências e lutas da educação do campo colocam em evidência a histórica desigualdade educacional da sociedade brasileira, em que os trabalhadores são os que possuem menor escolaridade. Também, dão ênfase aos diversos problemas estruturais e conjunturais, tais como concentração da terra e dificuldades materiais para a efetivação da produção agrícola e geração de empregos nas pequenas propriedades e nos assentamentos de reforma agrária, entre tantas outras. (SOUZA, 2012, p. 752).

A autora destaca que:

Um dos impactos e desafios das lutas da educação do campo é o reconhecimento da diversidade de trabalhadores do campo brasileiro no momento de elaborar políticas educacionais. Afinal, discutir identidades e culturas tão específicas como a dos indígenas, povos das florestas, ribeirinhos, caiçaras, ilhéus, quilombolas, faxinalenses, assentados, acampados, mulheres camponesas, entre outras, exige esforço pedagógico e político. Corre-se o risco de mascarar as diferenças e diversidades em nome da igualdade. (SOUZA, 2012, p. 760).

Nesse viés, com base em Arroyo (2006), uma reflexão se faz necessária: Que escola será educadora desarraigada do solo cultural dos educandos? O autor pontua que os movimentos sociais 
Afirmam direitos. Se afirmam como sujeitos de direitos Um dos traços mais instigantes dos movimentos sociais do campo não é pedirem escolas, nem favores, nem sequer pedirem suprir carências educativas. Colocam sua educação e a educação dos jovens e adultos, das crianças e adolescentes do campo no plano de direitos universais como cidadãos, como sujeitos humanos, políticos, culturais. (ARROYO, 2006, p. 12).

Para Arroyo (2009), o movimento social do campo é educativo, pois “[...] a escola está na fronteira de direitos e não no espaço estreito do mercado” (ARROYO, 2009, p. 72). A terra produz gente, pois produz trabalho, produção de vida, de família, de comunidade.

Um projeto de educação básica do campo tem de incorporar uma visão mais rica do conhecimento e da cultura, uma visão mais digna do campo, o que será possível se situarmos a educação, o conhecimento, a ciência, a tecnologia, a cultura como direitos e as crianças e jovens, os homens e mulheres do campo como sujeitos de direitos. (ARROYO, 2009, p. 82).

Segundo Neto (2011), os cursos de licenciatura em Educação do Campo “[...] devem incrementar o diálogo entre os vários saberes, incentivando, sempre com respeito, os saberes presentes em todas as culturas, seja a tradicional ou a técnico-científica”. (NETO, 2011, p.34).

O autor assevera que os projetos para a Educação do Campo devem:

Basear-se nos direitos sociais e ser centralizados na formação integral, não fragmentada, plural, democrática, coletiva, solidária, que incorpore novos valores críticos [...] Devem ser centralizados na formação pelo trabalho humano realizado no campo, ser uma educação vinculada aos interesses de todos os que se preocupam com a superação do atual estado capitalista e se propor a construir novas relações sociais e pedagógicas. (NETO, 2011, p. 37).

Frente a essa discussão, o que traz à tona são questões necessárias ao debate e resgatam a necessidade dessa luta para a inclusão desses sujeitos muitas vezes segregados dos seus direitos, bem como da abertura de editais específicos para a criação das licenciaturas com o objetivo de formar professores nas especificidades do contexto campesino, que possibilitem a sua permanência na universidade, para que a sua formação possa reverberar em ações na prática docente, nas escolas do campo, com vistas a sua melhoria e qualidade.

\section{$4 \mathrm{O}$ que temos? O que queremos? O que é garantia de direitos?}

Sabemos que o Ministério da Educação, na criação de projetos e programas, possibilita as instâncias educacionais à inclusão, mas cabe a cada instância cumprir esse papel de conduzir e efetivá-las em seu interior. Por isso, importante se faz indagar: O que temos? O que queremos? O que é garantia de direitos? 
PIATTI, Célia Beatriz. Licenciatura em Educação do Campo: espaço de garantir direito humano

Algumas questões nesse curso em pauta apontam para a inclusão. A primeira delas diz respeito à forma de ingresso dos acadêmicos via edital específico, que garante o ingresso de quem vive e/ou trabalha no campo ou de alguma forma tem vínculo com o campo, seja como professor ou membro de associações, ou de movimentos sociais. Outra se refere à contratação de quinze docentes em edital próprio com exigências de conhecimento referentes à Educação do Campo, com formação nas áreas específicas que são ofertadas para os acadêmicos (Matemática, Linguagens e Ciências Humanas e Sociais).

Há ainda a garantia, em calendário, da modalidade de alternância com carga horária de $60 \%$ de tempo universidade e $40 \%$ tempo comunidade e a superação do ensino disciplinar e fragmentado na formação docente, com diálogo permanente entre as disciplinas. Essas questões favorecem o ingresso dos acadêmicos, mas há desafios a serem superados, garantias a serem conquistadas.

Ainda temos desafios que nos afrontam dia a dia no interior da universidade, que afastam os acadêmicos e que rompem com a sua permanência no curso, são eles: a falta de estrutura física que possa garantir a alternância na prática, com alojamentos que possam acomodá-los no tempo universidade, que são tempos concentrados que exigem a permanência dos discentes na universidade e, portanto, na cidade onde está localizada. Há alojamentos na universidade, mas não são ainda bem estruturados, são adaptados, pois antes serviam como vestiário para jogadores, uma vez que estão localizados próximo ao estádio de futebol que fica localizado no interior da universidade.

Outra dificuldade é a de concluir a alternância com o instrumento de visita às comunidades realizadas pelos docentes, por falta de recursos financeiros, disponibilidade de motorista da universidade e carros que possam suportar os locais de difícil acesso.

Há também entraves com as secretarias de educação, que ainda resistem na liberação de seus professores para participarem da formação ou em relação ao estabelecimento de parcerias para ampliar o trabalho dos docentes no tempo comunidade.

Acreditamos que o maior desafio é a garantia de continuidade do curso que, no ano de 2018, institucionalizou-se e passou por alterações em seu projeto, sendo reconhecido no interior da universidade como um curso "padrão", como os demais cursos da universidade, interferindo, assim, na lógica e dinâmica da pedagogia da alternância, que incide na caracterização do curso e de um direito de quem trabalha no campo.

Outro desafio é a exclusão da área de Ciências Humanas e Sociais, com oferta apenas de duas áreas (Matemática e Linguagem) e a redução de oferta de vagas, de 120 para 30 vagas (15 para 
cada área). A redução de vagas se caracteriza em reduzir a entrada de acadêmicos advindos do campo e, portanto, da inclusão e da garantia de seus direitos, em especial, à educação. A justificativa de redução de vagas é a falta de alojamentos para os acadêmicos e a falta de repasse de recursos financeiros via Ministério da Educação.

A luta pela Educação do Campo acontece constantemente e, na universidade, torna-se um embate frente à exclusão em diferentes formas e configurações. Esse fato aponta aos gestores e aos docentes dessa licenciatura um compromisso social e político que requer a ruptura com o sistema ou a exclusão desses sujeitos, que possuem o direito de ingressar na universidade, mas têm o direito cerceado de permanecer nela.

Frente ao discurso da inclusão está a ausência de garantia dessa permanência, uma vez que, sem o rompimento com esse sistema excludente, o ingresso desses sujeitos não garante a permanência, a continuidade e uma formação que garanta no campo uma educação gratuita, de qualidade, com professores conscientes do seu papel nas escolas do campo.

Consciência essa que perpassa não apenas os conhecimentos científicos necessários à ação docente, mas o compromisso histórico com essa população. Uma educação que seja integral e emancipatória, que valorize o campo e que, segundo Molina (2012,p.249) “[...] não pode ser vista como lugar do agronegócio, da hegemonia do capital, ao contrário, deve ser vista como espaço de luta, de história de sujeitos, da contradição".

Por isso,

[...] não podemos deixar de reconhecer os avanços conquistados pela construção dos paradigmas e das práticas de Educação do Campo,que mesmo com enormes dificuldades, tanto em relação à repressão e à criminalização dos movimentos sociais camponeses que protagonizam quanto a relação à descontinuidade das políticas conquistadas, tem conseguido semear novos territórios, "territórios de esperança"(MOLINA, 2012, p. 249).

Territórios encharcados de esperança pela luta em direção à concretização de um direito que não seja apenas componente de um discurso vazio que remete a uma falsa ideia de inclusão, que, na realidade, é uma inclusão excludente e segregadora.

\section{Considerações finais}

Ao compreender a Educação do Campo como direito humano e social, é preciso romper com a crença que "[...] para mexer com a enxada ou cuidar do gado não são necessários nem letras e nem competências. Não é necessária a escola, ou seja, não há um reconhecimento da educação do Campo como um direito humano.” (PIRES, 2012, p. 13). 
PIATTI, Célia Beatriz. Licenciatura em Educação do Campo: espaço de garantir direito humano

Ao romper com essa crença frente ao percurso desse estudo, consideramos que, ao responder às indagações iniciais, quer seja:Ao garantir o ingresso dos acadêmicos na universidade, há a garantia de permanência? O discurso da inclusão é questionado no seio da universidade? Como a universidade tem garantido essas políticas de inclusão? É possível considerar que há avanços, mas também há muitos desafios.

Essa caminhada que percorreu a Educação do Campo, nos documentos oficiais, nas resoluções, nos pareceres, nas diretrizes e nas conquistas de intensas lutas ainda esbarra em estruturas para as quais a representação de campo está arraigada no desenho do campo como território atrasado e, por isso, o agronegócio é apontado como o favorecedor do progresso, o que permite confirmar cada vez mais a hegemonia do capital, a desvalorização dos camponeses e, nessa conjuntura, a própria desvalorização dos saberes que brotam desse trabalho e que, nessa configuração de educação que discutimos aqui, merece e deve ser valorizada.

Cabe então questionar a ação da universidade frente à abertura de um curso, sem recursos do Ministério da Educação: Como incluir se não há condições para a permanência? Essa resposta nos leva a entender que a luta está cada vez mais premente. Não há inclusão, não há permanência, não há garantia de direitos. Portanto, cabem outras discussões que precisam ser respondidas: Em um campo permeado de conflitos, como a escola vai construir a sua identidade? Como os professores vão compreender a escola como espaço formativo nessa luta pela Educação do Campo? Como as propostas pedagógicas das escolas se constituirão em harmonia com a história dos trabalhadores do campo? Questões que nos permitem buscar outras, pois concordamos com Pires (2012) que a formação docente é um processo em permanente construção “[...] permeada de contradições e determinada por condições objetivas e subjetivas, em que os sujeitos sociais vão se constituindo” (PIRES, 2012, p.109). Cabe ainda, ancorados em Schuchter e Carvalho (2017, p.140) indagar: "Quais os sentidos atribuídos à palavra inclusão? Quais os significados das políticas inclusivas? Por que, contraditoriamente, o conceito de inclusão surge com a mesma força que os mecanismos de exclusão social? Por que gerar processos de exclusão de pessoas que posteriormente deverão ser incluídas"?

Indagações que, neste estudo, revelam a necessidade de reconhecer a universidade como lugar de inclusão, mas, principalmente, lugar de conhecer a história da Educação do Campo, cujos sujeitos articulados aos movimentos sociais possuem a garantia de direito à terra, ao trabalho e, no interior da universidade, o direito à educação e, nesse sentido, o direito à educação do campo como direito humano e social. 


\section{Dialogia}

PIATTI, Célia Beatriz. Licenciatura em Educação do Campo: espaço de garantir direito humano e social

\section{Referências}

ARROYO, M. G. A Educação Básica e o movimento do social do campo. In: ARROYO, M. G; CALDART, R. S; MOLINA, C. M. (org.) Por uma Educação do Campo. Petrópolis, RJ: Vozes, 2009.

ARROYO, M. G. Prefácio. Educação do Campo: propostas e práticas pedagógicas do MST. Petrópolis, RJ: Vozes, 2006.

ANTUNES-ROCHA, M. I; MARTINS, M. de. F. A; MARTINS, A. A. (Org.). Territórios Educativos do Campo: escola, comunidade e movimentos sociais. Belo Horizonte: Autêntica Editora, 2012. (Coleção Caminhos da Educação do Campo).

CALDART, R. S. Por uma educação no campo: traços de uma identidade em construção. In: KOLLING, E. J; CERIOLI, P. R; CALDART, R. S. (Org.). Educaşão do Campo: identidade e Políticas, Brasília, DF: articulação nacional por uma educação do campo, v.4, 2002.

CALDART, R. S. (Org.). Caminhos para a transformação da escola: reflexões desde práticas da licenciatura em educação do campo. Expressão popular, 2011.

CALDART, R. S. A escola do campo em movimento. In: ARROYO, M. G; CALDART, R. S; MOLINA, M. C. (Org.).Por uma Educação do Campo. Petrópolis, RJ: Vozes, 2009.

CORREA, D. M. das N; BATISTA, M. do S. X .Alternância no Ensino Superior; o campo e a universidade como territórios de formação de educadores do campo. In: ANTUNES-ROCHA, M. I; MARTINS, M. de. F. A; MARTINS, A. A. Tempo Escola e Tempo Comunidade: Territórios Educativos do Campo: escola, comunidade e movimentos sociais. Belo Horizonte: Autêntica Editora, 2012. (Coleção Caminhos da Educação do Campo).

FERNANDES, M. B. Diretrizes de uma caminhada. In: CALDART, R. S. (Org). Por uma educaşão do Campo. Petrópolis, RJ: Vozes, 2009.

FERNANDES, B. M; CERIOLI, P. R; CALDART, R. S. "Primeira Conferência Nacional 'Por uma educação básica do campo': texto preparatório”. In: ARROYO, M. G; CALDART, R. S; MOLINA, M. C. Por uma educação do campo. Petrópolis: Vozes, 2009.

FUNDAÇÃO UNIVERSIDADE FEDERAL DE MATO GROSSO DO SUL. LEDUCAMPO. Projeto Pedagógico do Curso de Licenciatura em Educação do Campo. Campo Grande, 2014.

LEONTIEV, A. O desenvolvimento do psiquismo. São Paulo: Centauro, 2004.

MINISTÉRIO DA EDUCAÇÃO. Diretrižes Operacionais para a educação básica nas escolas do campo. Brasília, 2002.

MOLINA, C. M.Possibilidades e limites de transformações da escola do campo: reflexões suscitadas pela Licenciatura do Campo- UFMG.In:ANTUNES-ROCHA, M.I,MARTINS, A. A.(org.) Educação do Campo:desafios para a formação de professores.Belo Horizonte: Autêntica, 2011. 


\section{Dialogia}

PIATTI, Célia Beatriz. Licenciatura em Educação do Campo: espaço de garantir direito humano

MOLINA, C. M. Cultivando princípios, conceitos e práticas. Presença Pedagógica, Belo Horizonte, v.15, n. 88, p. 30-36, jul./ago. 2009.

NETO, A.J de M. Formação de professores para a Educação do Campo: projetos sociais em disputa. In: ANTUNES-ROCHA, M. I, MARTINS, A. A. (org.) Educação do Campo: desafios para a formação de professores, Belo Horizonte: Autêntica, 2011.

PIRES, A. M. Educação do campo como direito humano. São Paulo: Cortez, 2012. (Coleção e Educação de Direitos Humanos v. 4).Editora, 2012.

SACRISTÁN, G. J. A educação obrigatória: seu sentido educativo e social; tradução: Jussara Rodrigues. Porto Alegre: ARTMED editora Ltda, 2001.

SOUZA, M. A. Educaşão do campo, desigualdades sociais e educacionais. Educ. Soc., Campinas, v. 33, n. 120, p. 745-763, jul.-set. 2012. Disponível em http://www.cedes.unicamp.br. Acesso em jan. de 2020.

SCHUCHTER, T. M; CARVALHO, J. M. Políticas de inclusão: Avanços no campo da educação ou armadilhas do discurso neoliberal? Revista Teias, v. 18, n. 48, Jan/Mar. 2017. Disponível em: https://www.e-publicacoes.uerj.br/index.php/revistateias/article/. Acesso em jan. de 2020.

Recebido em: 28 mar. 2020/ Aprovado em: 17 ago. 2020

\section{$\underline{\text { Cite como }}$}

(ABNT NBR 6023:2018)

PIATTI, Célia Beatriz. Licenciatura em Educação do Campo: espaço de garantir direito humano e social. Dialogia, São Paulo, n. 35, p. 182-199, maio/ago. 2020. Disponível em:

https://doi.org/10.5585/dialogia.n35.16901.

\section{American Psychological Association (APA)}

Piatti, C. B. (2020, maio/ago.). Licenciatura em Educação do Campo: espaço de garantir direito humano e social. Dialogia, São Paulo, 35, p. 182-199.

https://doi.org/10.5585/dialogia.n35.16901. 